\title{
FANTASMAS O REVENANTS EN EL MEDIEVO: ANTECEDENTES DE ELEMENTOS FANTASMAGÓRICOS EN EL FoRMICARIUS DE J. NIDER
}

\author{
Carme Agustí Aparisi ${ }^{1}$ \\ Universidad Católica de Valencia San Vicente Mártir
}

Recibido: 28 de noviembre de 2019

Aceptado: 25 de mayo de 2020

\begin{abstract}
Resumen
Proponemos en este artículo explorar antecedentes de elementos fantasmales en la Edad Media mediante la tratadística didáctico-moralizante de la época. Desde la antigüedad, la mayoría de apariciones se vehiculaban mediante los sueños. Posteriormente y con el cristianismo, serán propios de la cultura medieval temas macabros como el de los tres muertos, que se manifestarán a los tres vivos para advertirles de la fugacidad de los placeres mundanos. En el medievo aparecerán muertos reclamando un buen entierro, clamando venganza por su muerte, o bien, simplemente incordiando y burlándose de los mortales. Para constatar todo esto, analizaremos relatos del tratado de Johannes Nider, el Formicarius (1437-38), importantísimo no solo porque sirvió de base al posterior Malleus Maleficarum (1486-87), sino porque se trata de la primera exposición sistemática que se escribió sobre estos temas: apariciones de fantasmas, casos de brujería, endemoniados y exorcismos.
\end{abstract}

\section{Palabras clave}

Formicarius, fantasma, espíritu, J. Nider, tratadística demonológica.

\begin{abstract}
In this article we aim to explore the background of ghostly elements in the Middle Ages through the didactic and moralising treaties at the time. Since ancient times, most of the appearances of such elements have been in dreams. Later, with the advent of Christianity, medieval culture came to be characterised by macabre themes such as that of the three dead who appeared to the three living to warn them of the transience of worldly pleasures. Throughout the Middle Ages, the dead might show up to demand a good burial or revenge for their deaths, or simply to bother or mock mortals. In order to prove all the above, we analyse the stories contained in Johannes Nider's work, Formicarius (1437-38), which is important not only because it served as the basis for the subsequent Malleus Maleficarum (1486-87), but also because it represents the first systematic treatise written on these topics: appearances of ghosts, cases of witchcraft, demoniacs and exorcisms.
\end{abstract}

\footnotetext{
Departamento de Lengua y Literatura. Facultad de Magisterio y Ciencias de la Educación. Universidad Católica de Valencia San Vicente Mártir. Correo electrónico: carme.agusti@ucv.es. OrCid: https://orcid. org/0000-0002-6383-346X.
} 


\section{Keywords}

Formicarius, ghost, spirit, J. Nider, demonology treatise.

\section{Résumé}

Nous nous proposons dans cet article d'explorer les antécédents d'éléments fantasmatiques au Moyen Âge à travers le traitement didactique et moralisant de l'époque. Depuis l'Antiquité, la plupart des apparitions étaient transmises par les rêves. Ultérieurement, avec le christianisme, la culture médiévale fera siens des thèmes macabres tels que celui des trois morts, qui se manifestent aux trois vivants pour les prévenir contre la fugacité des plaisirs mondains. À l'époque médiévale, on verra se manifester des morts réclamant une sépulture, criant vengeance contre ceux qui ont causé leur mort, ou simplement harcelant des mortels et se moquant d'eux. Nous illustrerons notre propos à partir des récits du traité de Johannes Nider, le Formicarius (1437-38), qui a servi de base au Malleus Maleficarum (148687), mais aussi parce qu'il s'agit de la première exposition systématique écrite sur ces thématiques : apparitions de fantômes, cas de sorcellerie, possessions et exorcismes.

\section{Mots clés}

Formicarius, fantôme, esprit, Moyen Âge, traités de démonologie.

\section{Introducción ${ }^{2}$}

La muerte ha estado presente, desde la antigüedad, conformando la creencia colectiva sobre los revenants ${ }^{3}$ o retornados. Y esta misma convicción ha posibilitado que el retorno de los muertos haya influido en el miedo de los pueblos a la hora de relacionarse con el proceso de la muerte. Esta siempre ha sido un misterio para el hombre primitivo, que observaba cerrarse un círculo mágico-religioso de pensamientos ancestrales a los cuales se enfrentaba con métodos propios de rituales mortuorios que propiciarían el descanso eterno del difunto. El retorno de los muertos estaba presente, por tanto, en su vida cotidiana, y dependiendo de si el muerto había tenido una buena o una mala muerte, la relación de los vivos con los difuntos podía ser completamente diferente. La creencia en fantasmas supuso, desde el principio, experiencias de contacto entre dos mundos: el de los vivos y el de los muertos, donde la memoria de aquellos que partían

\footnotetext{
2 El presente trabajo se inscribe en las actividades del Proyecto de I+D del Programa Estatal de Generación del Conocimiento y Fortalecimiento Científico y Tecnológico del Ministerio de Ciencia, Innovación y Universidades (cofinanciado por la Unión Europea a través de FEDER) PGC2018-095757-B-I00: Magia, Épica e Historiografía Hispánicas: Relaciones Literarias y Nomológicas, dirigido por el Dr. Alberto Montaner. Del mismo modo, forma parte de las actividades del grupo de investigación "Humanidades digitales: Nuevos recursos para la investigación y la enseñanza de la Historia" de la Facultad de Magisterio y Ciencias de la Educación de la Universidad Católica de Valencia San Vicente Mártir. Así como también del Proyecto "Figuras de lo insólito en la cultura de los márgenes: fascinación y horror en el mundo hispánico (siglos XVII-XIX), financiado por la Conselleria de Innovación, Universidades, Ciencia y Sociedad Digital.

3 Será Dom Augustin Calmet en el siglo XVIII y en su obra Traité sur les Apparitions des Esprits, et sur les Vampires, ou les Revenans de Hongrie, de Moravie, \&c. (1746), quien mejor identifique el término revenant cuando habla de los "vampiros" como revenants en corps, y los distingue de los revenants immatériels que son los espíritus de algunos muertos que vuelven del Más Allá.
} 
representaba, bien la bendición de los antepasados, o bien un suplicio que se tenía que solucionar, los muertos nunca podían estar descontentos. La muerte, como el fantasma ${ }^{4}$, fascinan y simbolizan la esperanza en otra vida. Desde la antigüedad estas creencias configurarán relatos y leyendas que asimilará el cristianismo con la teoría del alma. Así, con la aparición de los tratados medievales, se crearán unos motivos literarios que podremos considerar el germen de los cuentos de fantasmas del siglo XIX y XX. Ya en la antigua Mesopotamia se creía en espíritus maléficos que provocaban la enfermedad, que era causada por espectros o fantasmas llamados etemmu, individuos fallecidos en condiciones anormales. Entidades que estaban condenadas a vagar para siempre, que no podían alcanzar su reposo y que atemorizaban a los seres vivos produciéndoles toda clase de males. Para todos estos espectros, los griegos acuñarán un término: los daimones, "seres o espíritus sobrenaturales capaces de perjudicar, aunque también, a veces, de ayudar a los humanos" (Delgado 2014: 26).

Las representaciones de fantasmas en las tragedias griegas eran muy importantes en los espectáculos de las diferentes épocas. Encontramos algunos ejemplos como el fantasma de Clitemnestra en Euménides que se aparece al coro de las Erinias cuando duermen y las incita a despertarse para continuar la tarea de perseguir a Orestes ${ }^{5}$. La aparición del fantasma forma parte del sueño de las Erinias, y el motivo de su presencia es la venganza, Clitemnestra no puede descansar porque su muerte ha sido violenta y aún no ha sido vengada. Como nos dice Aguirre (2006: 117), "su ocasional presencia en sueños indica esa falta de corporeidad o de poder físico, pues ya desde Homero los fantasmas se caracterizan por ser insustanciales".

Recordemos, pues, antes de seguir con nuestro análisis, que los motivos de la vuelta de los muertos podían ser diversos, pero que se repiten desde la antigüedad hasta prácticamente nuestros días. Estas causas podían ser: no ser enterrado adecuadamente; volver para pedir venganza por una muerte violenta; los que mueren insatisfechos; los que mueren violentamente; aquellos que vuelven para advertir (benignos); para pagar una deuda; avisar de una enfermedad; aquellos que morían prematuramente; los suicidas; o los ahogados, entre otros. En la antigua Roma también los bebés y niños muertos, los condenados, suicidas o muertos por amor (Bardel 2005; Delgado 2014; Buxton 2014; Ogden 2014). "Los insepulti, a veces también llamados «los que no han sido llorados» [...] forman el grueso de la tropa de aparecidos y fantasmas" (Lecouteux 1998: 27).

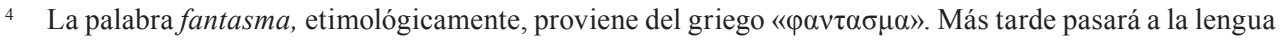
latina como «phantasma». Entendemos por fantasma, según el diccionario de la Real Academia Española: "2.m. Visión quimérica como la que se da en los sueños o en las figuraciones de la imaginación. 3.m. Imagen de una persona muerta que, según algunos, se aparece a los vivos". Acepciones ambas que aparecerán a lo largo de este artículo.

5 Las Euménides es una obra de Esquilo (siglo V a.C.) donde las Erinias, diosas de la venganza, persiguen a Orestes por la muerte de su madre Clitemnestra.

6 "Les insepulti, parfois encore appelés «ceux qu'on n'a pas pleurés » (indeplorati), forment le gros de la troupe des revenants et des fantômes" (Lecouteux 2009: 21).
} 
No podemos olvidar la historia de la amante fantasma de Flegón de Trales ${ }^{7}$ (siglo II) (De mirabilibus, I), donde una joven muerta y enamorada vuelve de la tumba por amor, un fantasma benigno que come, bebe y ama comportándose como una mujer viva. Relato de una gran importancia si consideramos su influencia posterior en la literatura, ya que será un antecedente de lo que posteriormente Goethe reescribirá con su relato (Die Braut von Korinth) La novia de Corinto (1797), aunque cambiará el final del cuento de Flegón transformando a la joven en vampira, inaugurando así la imagen literaria de la muerta viviente.

En la antigua Roma, las almas de los muertos podían convertirse en seres malignos que retornaban a la tierra e incordiaban a los vivos, atormentándolos y amenazándolos 9 Los laruae eran espíritus de difuntos malvados que no habían tenido una buena muerte (biaiothanatoi) y que regresaban al mundo de los vivos como "fantasmas" (Guzmán 2013). Por tanto, "en Roma, el muerto es considerado impuro y peligroso, y hay que congraciarse con él, o causará más de una fechoría ${ }^{10 "}$ (Lecouteux 1998: 26).

El relato de fantasmas más carismático de la antigüedad es el de Plinio el Joven ${ }^{11}$ (c. 61- c. 112), donde el motivo del fantasma en viviendas logra impactar al lector, iniciando los relatos de las casas abandonadas. Consideramos que el espectro que aparece en la casa tiene un componente sobrenatural, y posiblemente por esto, sea este cuento el primero en este tipo de relatos (García Jurado 2006). La historia tiene, evidentemente, todos los ingredientes de las narraciones de aparecidos de la literatura anglosajona ${ }^{12}$ : un fantasma que hace ruidos con cadenas; una casa encantada donde el ente atemoriza a todos los que osan acercarse; un mal enterramiento que al final, cuando sus restos

\footnotetext{
7 La joven Filinio, cuando todavía no habían pasado seis meses de su muerte, se aparece cada noche a Macates, apuesto forastero. Pasa la noche con el joven desapareciendo al alba. Come, bebe y duerme con su amado que no sabe que es un fantasma. Alertados los criados de la presencia de Filinio, avisan a los padres de esta que, al sorprender a los amantes, provocan la verdadera muerte de la muchacha. Macates, se suicidará víctima de la desesperación.

8 Goethe rescató la figura de la "novia vampira", que partía de la Antigüedad, dando un giro romántico hacia el folklore, al mundo medieval y a su literatura; iniciando así, el arquetipo literario de la vampira que se concretará definitivamente con la obra Carmilla (1872) de Sheridan Le Fanu.

9 Recordemos que en sus Fastos, el poeta Ovidio (siglo I d.C.) describía un antiguo ritual de las familias que dedicaban un día a sus difuntos, las Parentalia (celebrada en Febrero), que pretendían mantener contentos a los muertos.

10 "A Rome, le mor test tenu pour impur et dangereux, il faut donc se concilier ses bonnes grâces, dinon il commet plus d'un méfait" (Lecouteux 2009:20).

11 El filósofo Atenodoro llega a Atenas y alquila una casa donde se dice que se aparece un espectro. De noche, cuando todo está en calma, se presenta el espectro, con ruido de cadenas, llamándolo para que lo siguiera. Excavando donde el fantasma le dice, se encontraron huesos, atados con cadenas. Finalmente, sepultado el cadáver según el rito, el fantasma desapareció.

12 El tópico del fantasma en casa será ampliamente recurrente en la literatura anglosajona del siglo XIX, entre la gran cantidad de relatos podemos encontrar cuentos como: The Castle of Otranto (1764) de Horace Walpole, The House in Camden-Hill (1848) de Catherine Crowe, The Haunted and the Haunters or The House and the Brain (1859) de Edward Bulwer-Lytton, The Ghost of Lady Crowl (1871) de Sheridan Le Fanu, Winthrop's Adventure (1881) de Vernon Lee, The Open Door (1882) de Margaret Oliphant, The Canterville Ghost (1887) de Oscar Wilde.
} 
sean sepultados debidamente, desaparecerá; y la noche, elemento fundamental en las historias de fantasmas. Plinio, por tanto, contribuyó a asentar muchos de los motivos literarios que posteriormente caracterizarán los relatos de terror.

Pero en su Epistola (VII) Plinio cuenta dos historias más de aparecidos. La primera relata lo que le ocurrió a Curcio Rufo y se cuenta que estando este en una provincia de África, y paseando una noche por un pórtico, vio a una mujer hermosísima de altura sobrehumana; diciéndole que ella era África, le aventuró su futuro y le dijo que viajaría a Roma, donde tendría grandes honores y que cuando regresara a esta provincia africana, moriría. Todo ello se cumplió, según afirma Plinio en este primer relato. En el segundo cuento se refiere a un espíritu burlón, y explica que un liberto que dormía con su hermano en la misma cama, mientras dormían, a su hermano le pareció ver a alguien sentado en el lecho, y que cuando despertó se encontró rapado y con los cabellos en el suelo. Un claro ejemplo de una historia de visones durante el sueño.

Como podemos apreciar, el sueño es tema recurrente, durante esta época de la presencia de fantasmas que auguran y avisan de hechos que ocurrirán. También en el relato de Propercio (c. 50 a.C.-c. 2 d.C.), en Carmen (IV), el autor utiliza este recurso para narrar el lamento de la amada por la nostalgia del amor, que le reprocha a su amado haberla dejado morir por envenenamiento, una mala muerte que la lleva a vagar eternamente. $Y$ será durante la noche cuando su presencia y su lamento se hagan visibles: "Las almas errantes aparecemos de noche; la noche libera las sombras cautivas y el mismo Cancerbero vaga una vez que se ha abierto el cerrojo. La justicia nos ordena que al amanecer volvamos a la laguna del Leteo cuyas aguas provocan el olvido" (Gail et al. 2010: 41). Por tanto, podemos afirmar que la mayoría de motivos literarios de la tradición occidental del fantasma que perdurarán en el tiempo, ya estaban presentes en la cultura greco-latina, concretamente en las historias que hemos referenciado. El motivo de la casa encantada, donde el espectro se aparece para atemorizar; los ruidos y estrépitos nocturnos provocados por los espíritus; el muerto que no reposa porque no está enterrado convenientemente; o que vuelve para vengarse de quien provocó su muerte; los espíritus de los campos de batalla que conformarán, como ya veremos, ejércitos fantasmales que purgan sus pecados haciendo peregrinaciones; la aparición de fantasmas proféticos que anuncian una desgracia o anticipan una enfermedad; el del muerto que está agradecido y regresa para proteger a su benefactor. Son elementos fantasmagóricos que ayudarán a configurar el arquetipo gótico del fantasma. Todo ello amparado por la noche, pues la noche provoca terror por sí misma, por su oscuridad, su soledad y su misterio ${ }^{13}$.

\footnotetext{
13 Encontramos más historias de fantasmas en la antigüedad como las de: Homero (siglo VIII a.C.), cuando Ulises invoca a los muertos en la Odisea. La casa encantada de Luciano de Samósata (siglo II d.C.). En Plutarco, (segunda mitad s. I d.C.) que, en sus Vidas paralelas, relata como en la Vida de Bruto se le aparece un demonio que parece ser el fantasma de Julio César. En Lucano, (primera mitad s. I d.C.) que en su Farsalia detalla uno de los primeros actos de necromancia. En Apuleyo (siglo II d.C.), con su Asno de oro, donde aparecerá un fantasma vengativo. En Proclo (siglo V d.C.), con su Amante fantasma que abandona su tumba por amor. O en Filóstrato (siglo I d.C.), que nos habla de La lamia de Corinto (para más información y la lectura de los textos consultar bibliografía: Alejandra Guzmán Almagro).
} 


\section{La época medieval. Del paganismo al cristianismo y la transformación de los motivos fantasmales}

La evolución de las creencias paganas griegas y romanas hacia el cristianismo representará una aculturación de estas convicciones para, progresivamente, adaptarlas a las verdades cristianas. El cristianismo y la práctica de los ritos funerarios posibilitarán poder abrir una puerta al retorno de los muertos. La concepción de la muerte desde la antigüedad englobaba: nacimiento, vida y muerte; con la cual se cerraba el círculo vital, pero "las ideas de tránsito, de renacer nuevamente tras la muerte, no se perdieron a lo largo de los siglos, sino que se reafirmaron con la llegada del cristianismo" (Porras 1993: 10). Para que el alma descanse en paz y no haya retorno de los muertos, en la Edad Media aparecerán conceptos como el de la Buena Muerte o Ars moriendi.

Ars moriendi eran los cuidados que debían procurarse a un moribundo para su eterno descanso. Se creía que en la hora de la muerte, si no había una Buena Muerte, el demonio podía atormentar al moribundo, haciéndole perder su alma (Haindl 2013). Una valiosa referencia de la época para el bien morir será la obra de Jean-Charlier Gerson que en su De Scientia bonae mortis (1403) describe los cuatro pasos para una buena muerte: 1 . Aceptar la muerte, 2. El arrepentimiento, 3. Pedir misericordia a Dios, 4. Guiar la labor del asistente (Haindl 2009). Entre los rituales funerarios y tal como nos refiere Lecouteux (1998), existía la costumbre de cerrar la boca y los ojos del cadáver para que el espíritu abandonara el cuerpo del difunto, y este no pudiera ser ocupado por un demonio.

La muerte aterra, pero el posible retorno, aún más. Siempre se intenta que el muerto no regrese de la tumba, bien poniendo un alfiler en el sudario para que no pueda escapar, o bien dando una puntada; atando los dedos gordos de los pies juntos para evitar que el muerto se alce; o atando las manos con un rosario, consecuencia de la cristianización de los rituales paganos. Y cuando todos estos rituales no funcionen, la medida más frecuente es el degüello, ya que la cabeza es la sede de todas las acciones. En el proceso de cristianización de los rituales también aparecerán el sonido de las campanas, una cruz sobre el pecho del difunto, los rezos y la luz, que representa la simbología de la oposición a las tinieblas ${ }^{14}$. Como podemos apreciar, el miedo al regreso del difunto era muy real, en una época de crisis, peste, pobreza, guerras y desastres, la muerte era el fenómeno más presente de la cotidianidad medieval.

En todas estas creencias del retorno de los muertos, también contribuyó la teoría cristiana de la separación del cuerpo y del alma, así como la convicción en la resurrección de los muertos el día del Juicio Final, posibilitando así, que todas estas ideas arraigaran fuertemente en el subconsciente colectivo. La mediación, bien de Dios, bien del Demonio, llevará a una aceptación y a una naturalidad de la presencia de la muerte en la vida de la Edad Media. Asumido, pues, que hay apariciones, los teólogos medievales reformulan

14 En la Edad Media el pensamiento maniqueísta es una constante, la oposición entre el bien y el mal impregna toda la sociedad medieval. Arte de bien morir o mal morir; entre la luz (Dios) y la oscuridad (Demonio); el frío y el calor; la vida o la muerte. 
las teorías, aceptando que los muertos pueden volver siempre con el consentimiento divino. Así, cuando el regreso sea de santos se hablará de miraculum (hagiografías), y cuando el regresado sea poseído por un espíritu maligno, se hablará de demonio, pero siempre quedará claro que el retorno será por voluntad divina. Los demonios, por tanto, podían entrar en el cuerpo de un muerto y darle vida. Ya no se aparecerán en sueños, como en la antigüedad, y el muerto pasará a ser una entidad tangible la mayoría de veces. De ahí la importancia de un buen rito funerario.

Los responsables del proceso de cristianización de las ideas paganas fueron Tertuliano y San Agustín" ${ }^{15}$ ya que influenciarán con sus teorías a los teólogos de la Edad Media. "San Agustín justifica la creencia en los muertos que no tienen descanso, y en ese sentido es uno de los «Padres» de los fantasmas y aparecidos ${ }^{16}$ " (Lecouteux 1998:57). Nos da una primera definición del término al afirmar que el fantasma se aparece cuando apenas el hombre ha comenzado a dormir, está en un estado de duermevela, y cree estar viendo alguna forma que anda vagando desordenadamente. San Agustín nos dice que el hombre consta de dos sustancias: alma y carne, el alma es la razón y la carne los sentidos. La carne sin alma no tiene movimiento, pero el alma sí retiene su ser racional sin carne, lo que justificará, desde nuestro punto de vista, la creencia en fantasmas y aparecidos. Según Lecouteux (2009), para Tertuliano, las apariciones son obra indiscutible del diablo y son ilusiones que intentan burlar a los humanos. Diferencia, así mismo, entre "apare$\operatorname{cidos}^{17}$ " corpóreos y tridimensionales, y "fantasmas", entes evanescentes e inmateriales. Con todas estas imágenes de fantasmas, almas, aparecidos, o demonios, no hemos de olvidar que "en los siglos XII y XIII lo sobrenatural occidental se divide en tres dominios que designan aproximadamente los tres adjetivos, mirabilis, magicus y miraculosus, maravilloso cristiano" (Le Goff 2002: 15). Mirabilia sería el término que mejor designaría lo que entendemos hoy en día por maravilloso cotidiano, y las apariciones de los muertos se integrarían en un contexto real sin producir ningún tipo de alteración de la realidad. Lo maravilloso, como sobrenatural, representa lo maravilloso cristiano, es decir, lo milagroso; y lo mágico -la magia negra y la magia blanca-, cuando es magia negra, representa lo satánico.

\footnotetext{
15 Se pregunta San Agustín por la razón de la existencia de los espectros, y llega a la conclusión de que estos aparecen por medio de las artes mágicas y la intervención de los demonios si son espíritus malignos, es decir, que los demonios engañan. Hay buenos y malos espíritus, y los demonios hacen cosas maravillosas para atraer a los hombres. Pero en última instancia, las apariciones de muertos son por dispensación de la providencia de Dios. Los espíritus se aparecerán para: engañar, consolar o atemorizar. En una palabra, Dios puede permitir que los muertos vuelvan.

16 "Saint Augustin justifie la croyance aux morts sans repos, et il est en ce sens un des «pères» des fantômes et des revenants" (Lecouteux 2009: 51).

17 Es interesante recordar las diversas definiciones del término: Fantasma: "representación visual, acústica o táctil de un cuerpo no físico de una persona difunta, que no ha roto totalmente sus lazos con el mundo terrenal y deambula por él bajo forma no física". Espectro: "muerto que se aparece bajo una forma que provoca terror (esqueleto/cuerpo andante en descomposición)". Sombra: "imaginario hálito que se desprende de la boca del ser en el momento de su muerte". Espíritu: "concepción religiosa, manifestaciones de seres difuntos". Ánima: "concepto medieval cristiano de la larva". Aparición: "visualización del ser fallecido". Visión: "experiencia (sueño)" (Klein 2004: 7-8).
} 
En la Edad Media, los muertos que podrán convertirse en demonios, y por tanto, en espíritus malignos serán: los "fetos muertos, abortados, niños no bautizados, mujeres muertas durante el parto, muertas después del parto y antes de la cuarentena, prometidos muertos antes del matrimonio, o el día del matrimonio, suicidas, ahorcados, ahogados, y los que tengan una muerte violenta o no natural" (Delumeau 1989: 137), además de todos los referidos anteriormente. El cristianismo, pues, como podemos observar, substituirá y moldeará las creencias en espectros, dándoles una visión moral que integra la conciencia de redención y castigo, así como el arrepentimiento para poder alcanzar el goce de la vida eterna. Por todo esto:

Lo que domina la mentalidad y la sensibilidad del hombre medieval, lo que determina lo esencial de sus actitudes es el sentimiento de inseguridad. El peligro de condenación eterna, con la colaboración del diablo, es tan grande y las posibilidades de salvación tan escasas que el miedo prevalece necesariamente a la esperanza (Le Goff 1999:291).

Tópicos como el contemptus mundi, "el más absoluto desprecio hacia las cosas mundanas que implicaba la consiguiente miserabilización del cuerpo" (Mitre 2003-2004: 20), o el carpe diem, o vado mori, aparecerán en esta época. "Lo que más interesaba al hombre del siglo XV, no era tanto la vida cómoda en la tierra, sino el lograr una eternidad placentera" (Porras 1993:14). Y así, los tratados en la Edad Media servirán como "catalizadores y difusores de la cultura clásica medieval y en particular de la literatura sobrenatural" (Guzmán 2015: 566) porque a través de los exempla $a^{18}$, que servirán para asentar la teoría del castigo divino después de la muerte, estas historias se transformarán en relatos de fantasmas medievales.

El regreso de almas inquietas que clamaban sepultura o que acudían a vengarse y el mensaje de advertencia cumplían una función moralizante que podía catequizar de manera más efectiva. La descripción de los aparecidos, su aspecto terrorífico, sombrío o maltrecho, reforzaba su función instructiva (Guzmán 2017: 97).

Por tanto, los tratados demonológicos representarán una clara transmisión de las historias sobrenaturales de demonios-fantasmas, como ya veremos en nuestro análisis del Formicarius. La función de estas apariciones es, indudablemente, instruir a los vivos para corregir sus comportamientos erráticos, "por lo que se manifiestan a menudo

\footnotetext{
18 Los exempla según Schmitt (1994: 78) eran "récits qui, eux aussi, font appel au surnaturel, mais sans le souci d'une localisation précise (comme dans les miracula), en tirant au contraire de l'événement rapporté une leçon morale se voulant universelle".
} 
acompañados de señales terroríficas que reconducen con rapidez a los extraviados al buen camino, una vez asumida su pena sobrenatural” (Muñoz García 2014: 118).

Habrá pues, en la Edad Media, una gran cantidad de tratados y escritos demonológicos que relacionarán la presencia de los aparecidos o fantasmas con los demonios. Se escribirá sobre sus formas, causas, males, protecciones, remedios, prevenciones, o castigos; y serán muchos los autores que disertarán sobre estos temas. Uno de estos pensadores fue Cesáreo de Heisterbach (1180-1240), que en su Libri VIII, (48) de Dialogus Milaculorum (1223), relata en "Del lego que vio entrar en el coro a fantasmas del demonio" una historia de fantasmas:

Cierto hermano lego [...] vio al demonio en la figura del Prior, llevando una corona en el cuello como hecha de paja y legumbres. Le precedía uno de sus amigos tirándole de esa corona como si fuera un perro. Mientras tanto [...] ocurrió que entró en el coro el mismo Prior, para despertar a los legos que encontrara dormidos, y al entrar él, esa visión fantástica que el lego tenía ante los ojos, se desvaneció inmediatamente ${ }^{19}$.

Sobre las clases de demonios, Michael Psellos, ya en el siglo XI, en su obra Peri energeías daimónôn (Sobre la actividad de los demonios), afirma que "hay seis clases de demonios: ígneo, aéreo, terrestre, acuático y marino, subterráneo y lucífugo" (Flores 2008:7). A mediados del siglo XIII, Santiago de la Vorágine en su Legenda aurea recogerá multitud de relatos hagiográficos, pero también hablará de la muerte en $D e$ commemoratione mortuorum, concretamente sobre la fiesta de los muertos (Lecouteux 1998). Alfonso de Espina en 1458 publicará Fortalitium fedei, tratado de cinco libros; y en el Liber quintus et ultimus: De bello demonum, disertará sobre los demonios. Posteriormente, en el siglo XVI, encontraremos autores que continuarán reescribiendo las mismas teorías demoniacas que en siglos anteriores, favoreciendo y reimprimiendo historias de aparecidos y fantasmas. Fray Martín de Castañega en 1529 publica el Tratado de supersticiones y hechicerías y varios conjuros y abusiones y de la posibilidad y remedio dellas, donde hablará de ánimas atormentadas que pueden introducirse en los cuerpos de los vivos. Martín del Río recogerá y sintetizará en sus escritos todo el pensamiento medieval que se había generado sobre los aparecidos y su innegable relación con los demonios. "Los demonios son entes integrados en el mundo, y lo que hay que distinguir, entonces, es la magia buena o blanca (teurgia) y la mala o negra (goecia), según la clase de demonios buenos o malos que intervengan" (Martín del Río [15511608 (1991: 858)]. "Las almas de los muertos pueden y suelen en ocasiones aparecerse a los vivos, por el poder y virtud de Dios. Esto es conforme con las verdades de la fe católica y los dictámenes de la filosofía verdadera y genuina” (p.436) ${ }^{20}$.

19 Ver bibliografía.

20 Otros representantes de esta tratadística serían: Ludwig Lavater que publica en 1571 Trois libres des apparitions des esprits, fantomes prodiges et accidens merveilleux qui precedent souventes fois la mort 
El no reposo de las almas después de la muerte llevará a la configuración de la idea del Purgatorio, lugar intermedio entre el Cielo y el Infierno, donde los muertos -las almas que no han obtenido el reposo eterno- purgan sus pecados, esperando poder ser redimidas. En la Biblia, podemos encontrar antecedentes de lo que posteriormente será el Purgatorio en los siguientes pasajes: el primer texto pertenece a Zacarías (Za 13 8-9), que afirma: "en toda esta tierra -oráculo de Yahvé- dos tercios serán exterminados (perecerán) y el otro tercio quedará en ella. Meteré en el fuego este tercio: lo purgaré como se purga la plata, lo refinaré como se refina el oro". El segundo texto pertenece a la Primera epístola a los Corintios (1 Co 3 14-15), y dice:

Pero la obra de cada cual quedará patente; la pondrá al descubierto el Día, que vendrá acompañado de fuego. Y el fuego probará la calidad de la obra de cada cual. Aquel cuya obra, construida sobre los cimientos, resista, recibirá la recompensa. Más aquel cuya obra quede abrasada, sufrirá el castigo. Él, no obstante, quedará a salvo, pero como quien escapa del fuego.

Pero quien describirá el lugar con más precisión será San Agustín:

San Agustín se había preocupado en describir el lugar de tránsito donde acudían las almas tras la muerte en espera de Juicio; un espacio en el que debían purificarse para gozar de los beneficios del cielo, o bien descender hacia las torturas infernales. No fue hasta la época de Gregorio Magno, a mediados del siglo V, cuando ese espacio de purificación de las almas comenzó a tomar forma de lo que luego sería el Purgatorio (Guzmán 2017: 93).

Tal y como explica Le Goff (2002), el sustantivo purgatorium aparece en el último tercio del siglo XII. Este verdadero "nacimiento" del purgatorio se produce durante una gran mutación de la mentalidad y de la sensibilidad en el paso del siglo XII al siglo XIII, especialmente durante una modificación profunda de la geografía del Más Allá y de las relaciones entre la sociedad de los vivos y la sociedad de los muertos. La primera noción del Purgatorio (1190) se debe a un cisterciense inglés que escribió el tratado Purgatorium Sancti Patricii "la descripción de una creencia y una práctica que se sitúan en una isla, Station Island, en medio de un lago, el Lough Derg (el lago Rojo) en el norte del Eire actual, cerca de la frontera de Irlanda del Norte" (Le Goff 2002: 45). Y así, todas estas almas que "purgan" sus pecados necesitarán del mundo de

de quelque personnage renommé, [...]; donde recopila una amplia clasificación de «Esprits » y que en la página 147 nos habla de un capítulo titulado: Le Diable peut apparoir en diverses formes, \& faire choses merveilleuses. Así como Fra Nöel Taillepied que el 1602 publicará Traite de l'Apparition des Esprits. 
los vivos hechos que satisfagan a la justicia divina y posibiliten su redención ${ }^{21}$ : ayunos, penitencias, misas, y limosnas para los pobres.

Todas estas transformaciones acontecidas en el ideario medieval para adaptar las ideas y ritos paganos al cristianismo, comportarán una nueva concepción del arte que complementará la función didáctico-moralizante de los exempla y de los tratados, nuevas sensibilidades que también contribuirán a la creación de una nueva estética medieval. La presencia de la muerte y de los muertos, la insistencia en los buenos ritos funerarios, la cercanía de la muerte por condiciones naturales, propiciará dos fenómenos artísticos muy relacionados con la fugacidad de la vida. La muerte no solo se escribe, sino que el arte medieval entra de lleno en la muerte con dos representaciones importantísimas para la construcción de lo macabro: Las Danzas de la Muerte y El encuentro de "los tres muertos con los tres vivos".

Las Danzas de la Muerte representarán exposiciones artísticas y culturales muy acordes con esta época. Sus componentes, que nos presentan a la muerte como a la protagonista del espectáculo, hace que podamos visualizar el diálogo entre esta y los vivos que, con tópicos como el Ubi sunt?, y su crítica a la vanitas, permite contemplar la fugacidad de la vida terrena y la poca importancia que, al final, tiene la gloria mundana. Qué significa la muerte en las danzas: "el fin de la gloria terrenal, la descomposición de la belleza, el mensaje [...] que es inevitable para todos" (Haindl 2009: 132). Perdurará, no obstante, en las Danzas de la Muerte cierto paganismo ritual en la creencia del retorno de los muertos, espíritus de revenants, donde la escenificación de los cuerpos de danzantes hará ver que lo importante, al final, no es el cuerpo, sino preservar la salvación del alma.

Otro de los temas macabros de la Edad Media será el de "los tres muertos que se aparecen a los tres vivos ${ }^{22}$ " para advertirles de la fugacidad de los placeres mundanos, un claro antecedente de los aparecidos que regresan para advertir, prevenir o informar. Tres muertos que se representarán como podridos y comidos por gusanos. El encuentro de los tres muertos se enmarcará en los géneros didáctico-sapienciales, relacionados con los exempla de la literatura medieval. Este encuentro representa la "necesidad de conducir (la vida) por el recto sendero del buen comportamiento" (González-Zymla 2014: 182). Podemos encontrar un precedente del encuentro de "los tres vivos y los tres muertos", en la Biblia, en la profecía de Los huesos secos de Ezequiel, (Ez 37 1-14), que dice:

\footnotetext{
${ }^{21}$ Los vivos no deben nunca olvidar a los muertos por esto, a partir del siglo XI, será el Monasterio de Cluny quien fije la fecha en la liturgia, dedicando el día 2 de noviembre al culto de todos los muertos (Bueno 2015).

22 El tema de "los tres vivos y los tres muertos" hunde sus raíces tanto en el mundo clásico, como en la tradición budista de la India, y está relacionado directamente con los cuatro encuentros del príncipe Siddartha Gautama (Buda).Alejándose, de esta forma, de las raíces cristianas (González Zymla, 2011). Interesa para nuestro estudio, resaltar el término de "transculturalidad de lo macabro" que acuña González Zymla (2019) para hablar de las representaciones de "los tres vivos y los tres muertos" como testimonios materiales para estudiar la interculturalidad y la globalidad del arte de aquel tiempo, puesto que se dieron por igual en toda Europa. Así mismo, podemos hablar también de una "transculturalidad literaria de lo macabro" ya que estos tópicos pasaran a la literatura de la época y evolucionarán, posteriormente, hasta convertirse en motivos fantasmagóricos góticos.
} 
"Yahvé puso su mano sobre mí y, por su espíritu, me sacó y me colocó en medio de la vega, que estaba llena de huesos [...] Huesos secos, escuchad la palabra de Yahvé [...] voy a infundir en vosotros un espíritu que os hará vivir ${ }^{23}$ ".

Por último, para finalizar este repaso de la cosmogonía cristiana donde la vida es un tránsito hacia la eternidad del alma, donde la muerte tendrá una recompensa o un castigo, no podemos dejar de destacar la importancia de la iconografía de las Cántigas de Santa María de Alfonso X, que a finales del siglo XII y concretamente en su Cántiga LXXII, explicará la historia del muerto que se aparece a su padre, contribuyendo, así, a la literaturización de los temas macabros. La historia cuenta cómo un joven tahúr, enfadado por perder a los dados, maldice a Dios y a la Virgen. Es condenado y muere, y un demonio lo abre en canal. El padre lo encuentra y lo envuelve en un sudario para enterrarlo. El muerto se aparece para pedir una sepultura digna y cristiana, y así poder lograr su descanso eterno. Se avisa, con este relato, de que ofender a Dios y a la Virgen tiene consecuencias. Las imágenes de la cántiga respecto a la imaginería del muerto son excepcionales para la construcción del ideario colectivo del fantasma, ya que nos muestra al difunto envuelto en un sudario blanco o sábana, es un cadáver andante y translúcido que representa al muerto que vuelve para pedir su redención. Podemos afirmar que el fantasma occidental adoptará una de estas iconografías de la cántiga, pero habrá más; según Schmitt (1994), las imágenes de revenants que el ideario medieval nos transmitirá son las siguientes:

Le type de Lazare : le revenant est dépeint comme un ressuscité. Le type du mort dépeint comme un vivant (...) Le type de l'âme : (...) prend la forme d'un petit personnage nu (...) Le type du fantôme : (...) enveloppé dans un suaire diaphane. Le type macabre : (...) cadavre en état plus ou moins avancé de décomposition. L’invisibilité. (p. 235).

\section{El Formicarius y los relatos de Nider sobre fantasmas}

El Formicarius ${ }^{24}$ es un tratado de brujería, endemoniados y exorcismos de la Edad Media, escrito por Johannes Nider ${ }^{25}$ entre 1437-38. El autor pretende, con esta obra, recopilar testimonios maravillosos para demostrar y glorificar la grandeza de Dios que es el único obrador de milagros dentro de la Iglesia. Aunque también hemos de tener en cuenta que la misión de la obra es la de "educar" en la Fe cristiana ya que, el tratado quiere instruir al buen cristiano en el camino verdadero de la fe, guiándolo y fortaleciéndolo, presentando experiencias reales, con testimonios recogidos por los padres de

\footnotetext{
3 Para la lectura del texto completo, consultar Biblia de Jerusalén (bibliografía).

24 Para el análisis y los textos de nuestras reflexiones en este artículo hemos utilizado la segunda edición crítica (2019) del Libro Quinto del Formicarius de Pedro Eduardo León Mescua.

25 Johannes Nider fue un fraile dominico nacido hacia 1380 en Isny (Suabia), actual BadenWürttemberg, al sur de Alemania. Fue predicador en Colmar y Prior del convento de Núremberg en 1427-1429.
} 
la Iglesia, por personas concretas que cuentan sus historias o por el mismo autor. Así, tomando a las hormigas ${ }^{26}$ como alegoría, irá desgranando aspectos de la vida cristiana. El Formicarius se desarrolla como un diálogo entre el Theologus y el Piger $^{27}$ (el fraile), tomada aquí la expresión como referencia al estudiante en teología o el sacerdote, que necesita ser iluminado e ilustrado sobre cuestiones fundamentales de la fe cristiana.

El tratado está dividido en cinco libros, con doce capítulos cada uno de ellos. Nuestro estudio se centrará en el Libro V: De maleficis et eorum decepcionibus (Sobre los brujos y engaños), una detallada exposición sobre apariciones de fantasmas, casos de brujería, endemoniados y exorcismos, aunque focalizaremos en este estudio exclusivamente en el análisis de los relatos de fantasmas. El autor recopila numerosas experiencias que ha vivido personalmente o que ha recibido directamente de quienes lo vivieron en primera persona, y será la primera exposición sistemática que se escribió sobre estos temas. Nider trata de separar lo maravilloso que procede de Dios de aquello que puede originarse en nuestra fantasía o por medio del demonio, pues recordemos, como ya hemos visto anteriormente, que, en el cristianismo, el demonio puede obrar milagros y profecías, eso sí, siempre con el consentimiento divino.

En el Libro V cada capítulo sigue el siguiente esquema: se propone una característica de la vida de las hormigas que pueda ayudar a ejemplarizar el tema teológico que el autor tratará a continuación, después Nider propone ejemplos sacados de la Biblia o de las teorías de los santos Padres, y a partir de aquí será el Piger quien, a través de una pregunta a su maestro, posibilite que el Theologus -mediante el pensamiento del autor- exponga los temas concretos que a él le interesan. El objetivo primordial del autor, por tanto, al escribir el tratado es desenmascarar "el engaño diabólico", el cual puede asumir la apariencia de un difunto para hacernos creer que es el propio muerto el que se nos aparece. La creencia de que los espíritus de los difuntos se aparecen, sobre todo en sueños, a los vivos, es una convicción muy antigua, como ya hemos apreciado, pero, a veces, es Dios quien puede permitir que algunas almas justas se aparezcan a los vivos. Hemos de tener en cuenta que el Formicarius se enmarca dentro de los tratados didáctico-morales del buen comportamiento del cristiano frente a la vida y la muerte, y que sus exempla servirán para concienciar de los castigos o malos comportamientos que harán peligrar el poder alcanzar la gloria eterna.

También encontraremos, en el tratado, casos de fenómenos paranormales en viviendas como ruidos, sucesos inexplicables, o apariciones. Nider piensa que aunque, estos, suelen atribuirse a fantasmas, la única conclusión lógica es que se trata de demonios que importunan a los vivos. A veces, los fenómenos fantasmales son inofensivos, como en el caso de los silbidos, ruidos, o espíritus burlones; pero otras veces son apariciones violentas con agresiones físicas o posesiones demoníacas. Es verdad que, en siglos an-

\footnotetext{
26 Formicarius significa Hormiguero. Se tomarán las características de las hormigas, para ir analizando aspectos de la vida cristiana, ofreciendo una analogía entre la vida de las hormigas y el cristianismo.

27 El fraile llamado Piger, es llamado así porque en latín significa "perezoso". Se recoge, por un lado, el estereotipo del fraile ocioso y con tendencia a caer en el pecado (como demuestran muchos de estos relatos medievales) y, por otro lado, refiere a su necesidad de ser ilustrado en la materia.
} 
teriores, mucho se había escrito sobre el demonio, su caída, sus poderes y su jerarquía, pero nunca antes ningún teólogo ni filósofo había puesto los fenómenos de fantasmas, de la brujería y del exorcismo como punto central de su reflexión, y si es importantísimo este tratado es porque fue la principal fuente de inspiración del posterior Malleus Maleficarum $^{28}$ (1486-87). Tratado escrito por Heinrich Kramer y Jakob Sprenger, el Malleus fue el libro más importante contra la brujería que sirvió de manual inquisitorial en la llamada "caza de brujas" que se llevó a cabo entre los siglos XVI y XVII.

Estudiaremos, en este artículo, casos de apariciones de fantasmas sobre los que Nider reflexiona en el Capítulo 1 del tratado Colores diuersi quid in sacra Scriptura significant. quod tribus modis deluduntur hominum mentes. et de nocturnis exercitibus et equitibus: quid in bono uel in malo significent ${ }^{29}$. Así como también relatos del Capítulo 2 titulado Unde proueniant inquietudines nocte in quibusdam domibus; exempla ponuntur. Et quomodo fiunt possessiones hominum a denonibus. Ac de sex causis quare quídam non liberantur ${ }^{30}$.

Los relatos analizados serán: El pintor herido por un fantasma, El que cabalgó con un ejército de fantasmas, y El fantasma y el fraile.

\subsection{El pintor herido por un fantasma ${ }^{31}$}

En una iglesia de Colmar -municipio de Francia-, trabajaba un pintor que tenía una triple enfermedad: su color era como de muerto, estaba medio sordo y balbuceaba al hablar. Defectos que se atribuían a un fantasma, ya que "le fueron infligidos por un fantasma" (Nider 2019: 8). El relato nos cuenta que caminando una noche solo por unas viñas, se le apareció un espíritu, al que golpeó con su espada. Pero al golpear, nuestro

\footnotetext{
28 El Malleus pertenece al género de los Penitenciales y fue escrito por dos monjes dominicos. El libro está dividido en tres partes: la primera intentará probar que la brujería existe; la segunda describe las diversas formas de brujería; y la tercera detalla cómo detectar, llevar a juicio y castigar a las brujas. Tomará amplios capítulos del Formicarius para corroborar todas estas ideas, pero expresará con una gran misoginia sus opiniones sobre las mujeres y los aspectos brujeriles, misoginia que no apreciamos en el Formicarius.

29 Qué significan los diferentes colores en la sagrada Escritura. Tres modos en que son engañadas las mentes de los hombres. Y sobre los ejércitos y jinetes nocturnos: qué significan para bien o para mal.

30 De dónde provienen las perturbaciones en algunas casas de noche; se ponen ejemplos. Y en qué modo ocurren las posesiones de hombres por demonios. Así como sobre las causas por las que algunos no son liberados.

31 La historia es la siguiente: Preterea pictorem quendam in ecclesia nostra columbariensi laborantem habuimus, infirmitatibus tribus lesum. Nam in colore mortuo uidebatur similior quam uiuenti, semis urdus fuit auditu et multum in lingua balbuciens, quas infirmitates cum audissem sibi per quoddam fantasma inflictas. A pictore que seguuntur ipse audiui. "Cum -inquit- iunior in taberna cum sociis uersus noctem conuixissem, nocte tetra solus iter arripui, accinctus gladio, et uersus uillam aliam (quam michi nominauit) properaui. Uisum est autem mihi, cum essem inter uineas, quedam terribilia obuiare, non in ipso itinere sed prope uiam. Quo facto de itinere salii, gladium eduxi et uersus locum fantasmatis, iuuenili fatiutate et uini calore animatus, percussi in incertum. Cum autem neminem uiderem, in ipso ictu aerem, nescio quem, me pertranseuntem sensi, quo statim infectus, quas in me uidetis, infirmitates trinas contraxi.
} 
protagonista observó que no había nadie, aunque con el golpe sintió "un aire, no sé de qué tipo, que me atravesaba" (Nider 2019: 8), causa posterior de su triple enfermedad. Los elementos que podemos extraer del relato son los siguientes: La noche, parte fundamental de las historias de fantasmas desde la antigüedad que representa en el subconsciente colectivo el mal, identificable con lo desconocido y el imperio de los seres terroríficos. La soledad, la acción transcurre en un lugar concreto y real -Colmar-, así como en un contexto apartado - una viña-, y en un estado de soledad del protagonista, que, además, sale bebido de una taberna. Por tanto, la historia contada no tiene testigos -hecho muy común en la mayoría de cuentos de fantasmas-. Respecto al fantasma referido por el protagonista, este ente invisible e incorpóreo pero maligno, que transmite la enfermedad, es descrito como un aire, como un instante que atraviesa el cuerpo del personaje. Encontramos antecedentes, de este tipo de fantasma incorpóreo, en textos antiguos como la Odisea, cuando las almas que acuden a la invocación de Ulises se describen como un "remolino confuso". También en Homero, que utiliza el término "sombra" para referirse a los fantasmas, por su incorporeidad. Y en Lucano, que en su obra Farsalia, habla de una "sombra", siendo este cuento uno de los primeros textos literarios que contiene un acto de necromancia.

\subsection{El que cabalgó con un ejército de fantasmas ${ }^{32}$}

Celebrándose en Núremberg una Dieta de fe por el Reino de Bohemia, se convocó una reunión de obispos y doctores de las Sagradas Escrituras. Entre ellos se encontraba el Arzobispo de Maguncia, los obispos de Wurzburgo, de Augsburgo, y el de Bamberg "y yo, entre ellos el inferior y más humilde" (Nider 2019: 9). Será el Arzobispo de Maguncia quien relate la historia que dice así:

Un caballero de Renania, destacado sobre los nobles de Alemania, cabalgaba de noche por un bosque cercano al Rin e hizo avanzar a un criado por los lindes del bosque para observar si podía haber emboscadas. Adelantado el criado, vio "a lo largo del campo un ejército muy admirable que se acercaba a caballo" ${ }^{33 "}$ (Nider 2019: 10). El caballero avanzando se encontró con un jinete que sujetaba las riendas de otro caballo vacío, y reconociendo en el jinete a un cocinero suyo que había muerto, preguntó: "¿No eres tú mi cocinero?, "Soy yo, señor ${ }^{34 "}$ (Nider 2019: 10) respondió el otro. Preguntando a dónde iba ese gran ejército al que acompañaba, este respondió que eran nobles y soldados que viajaban hacia Jerusalén "porque esa es nuestra condena ${ }^{35 "}$ " (Nider 2019:10). Y preguntó el señor que para quién era el caballo que este llevaba vacío, "para vos señor, si queréis venir conmigo a Tierra Santa ${ }^{36 "}$ " (Nider 2019: 10). El caballero, desoyendo los

\footnotetext{
2 Para consultar la historia completa en latín ver: Johannes Nider (versión Pedro Eduardo León Mescua), pp. 9-11.

33 "uidit per campi longitudinem exercitum satis mirabilem properare in equis" (p.10).

34 "Numquid tu cocus meus est?" [...] "Sum, domine" (p.10).

5 "quia hec pena nostra est" (p.10).

36 "obsequium erit et si mecum ad Terram Sanctam uenire uultis" (p.10).
} 
consejos de sus criados, se montó en el caballo y "ambos jinetes fueron arrebatados ${ }^{37}$ " (Nider 2019: 11) ante los ojos de la comitiva. Al día siguiente, volvieron el caballero y el jinete -fantasma-, y el difunto dijo: "Para que no creáis que todo esto fue la ilusión de un fantasma, conservad en recuerdo mío estas dos cosas raras que os doy 38 " (Nider 2019: 11). Entonces le dio un pequeño paño de piel de salamandra y un cuchillo. El primero, dijo: "cuando esté sucio limpiadlo con el fuego y no se dañará. El otro manejadlo con cautela porque al que hiera será envenenado ${ }^{39 "}$ (Nider 2019: 11). Y así, el difunto desapareció de la vista del caballero.

Los elementos que podemos extraer del relato son los siguientes: La veracidad, que contextualiza el cuento en un lugar y una época concretas, Dieta de fe en el Reino de Bohemia, y en la ciudad de Núremberg. La autoridad, que asienta el relato en argumentos de personajes importantes de la iglesia: el Arzobispo de Maguncia, Obispos de Wurzburgo, de Augsburgo y de Bamberg, que con su presencia certifican y dan fe de que la aparición que se ha contado, no solamente es posible, sino que es creíble y ha pasado. El fantasma, que en esta historia es un muerto resucitado ${ }^{40}$ que pena por su mala conducta ${ }^{41}$ viajando por sus pecados para redimirse en Tierra Santa con un ejército nocturno de fantasmas. El tema del muerto resucitado o muerto viviente lo encontramos ya en la Inglaterra del siglo XII, donde se narran casos de revenants atribuidos al demonio, hombres malos que regresan de la muerte. Guillaume de Malmesbury (1080/1095 - ca. 1143), historiador medieval inglés, documentará historias de vampiros en la Inglaterra de esta época en su obra Gesta regum anglorum (1125) (Sharpe 1815). Así como Guillermo de Newbridge (1136-1198), que hablará de diversas "apariciones" en el territorio de Bukingham en Historia regum anglorum (Schmitt 1994). Respecto a

37 "ab oculis famulorum uterque equester subtractus est" (p.11).

38 "Ne fantasma omnino fictum illa fuisse credatis, duo que uobis do rara reseruate in mei memoriam" (p. 11).

39 "Primum -inquit- cum immundum fuerit, igni putgate nec ei nocebit. Alterum cute tractetis quia ab eo uulneratus intoxicatus erit" (p.11).

40 Respecto al muerto resucitado, el gran difusor de lo que posteriormente será el personaje literario del vampiro es Dom Augustin Calmet que en el siglo XVIII, asentará las características diciendo: Los revenans, vampires, oupires «sont des hommes morts depuis un temps considérable, quelquefois plus quelquefois moins long, qui sortent de leurs tombeaux \& viennent inquiéter les vivans» (Calmet 1751 cap. I, p.2). Calmet explicará casos investigados en el centro de Europa respecto a los enterrados vivos que, por diversas razones, han vuelto a la vida y hablará de los masticadores de sudarios y dará una perfecta descripción de sus características. En uno de sus relatos cuenta que en el pueblo de Kisilova, un anciano de 62 años, muerto tres días antes, se le aparecerá a su hijo y le pedirá comer (Vurdalak). Después del hecho, acontecerá la muerte del hijo y, fallecido este, el mismo día morirán 5 o 6 personas más del pueblo que primero habían enfermado. Abrieron las tumbas y: «Quand on vint à celui du Vieillard, on le trouva les yeux ouverts, d'une couleur vermeille, ayant une respiration naturelle, cependant immobile comme mort; d'où l'on conclut qu'il étoit un signalé Vampire. Le boureau lui enfonça un pieu dans le cœur. On fit un bûcher, \& l'on réduisit en cendres le cadavre. On ne trouva aucune marque de Vampirisme, ni dans le cadavre du fils, ni dans celui des autres» (Calmet 1751, cap. IX, pp. 40-41).

41 No olvidemos que el cristianismo había asimilado las viejas ideas sobre los espectros pero confiriéndoles una significación moral que se integraba en la salvación eterna del alma. Pero todo ello conllevaba una buena vida guiada por los preceptos cristianos, y quien se saltaba estos preceptos había de purgar sus penas para redimirse. 
los ejércitos de fantasmas ${ }^{42}$, en la antigüedad, Pausanias en Descripción de Grecia habla de "ejércitos espectrales"; también Julio Obsecuente en su Liber prodigiorum refiere la lucha de dos ejércitos fantasmales que se enfrentaban en la batalla. En el siglo X, el Exercitus antiquus, -ejército de fantasmas o almas del Purgatorio- se había consolidado entre los germanos a partir de la mitología guerrera representada en Wotan ${ }^{43}$-rey de los muertos-, que dirigía las almas en un viaje nocturno al otro mundo. Y el abad Regino de Prüm (ca. 840-915) recogió toda una serie de creencias populares pre-cristianas en el Canon Episcopi, entre ellas, la imagen de la cabalgada nocturna de las huestes (Lisón 1998). Por último, respecto a los elementos mágicos del relato (maravilia), para confirmar la veracidad de lo acontecido al protagonista, el fantasma le obsequia con dos elementos mágicos. La incursión de lo maravilloso, en el texto, vendrá explicada desde la perspectiva de lo "maravilloso cristiano", donde todo fenómeno sobrenatural, en este caso la aparición del muerto, así como los dos objetos mágicos que recibe el protagonista, tiene en última instancia una explicación religiosa.

\subsection{El fantasma y el fraile ${ }^{44}$}

En tiempos del Concilio de Constanza, en el Monasterio de Pillenreuth, en Núremberg, profesaban las hermanas Canonesas Regulares, y "un espíritu solía inquietar a muchos durante la noche ${ }^{45}$ " (Nider 2019: 23). No molestaba a las hermanas del convento, pero sí al capellán y a los lugareños, con "ciertos ruidos, silbidos y golpes"4" (Nider 2019: 23), un espíritu "burlón” que habitaba en las casas. Llamado un fraile para ayudar al capellán en sus funciones, fue acomodado en la parte alta de su casa, "ignorando lo del espíritu, sintió de noche que el fantasma le quitaba su túnica, que había puesto encima suyo ${ }^{47}$ " (Nider 2019: 23). Pensando el fraile que le robaban, comenzó a gritar y despertado el campanero que dormía en la misma casa, buscaron y buscaron por la habitación, pero no encontraron nada, solamente "las (la ropa) vio dispersas por el espíritu en la habitación"48" (Nider 2019: 23). Por ningún lado se encontraba el escapulario que el fraile tenía, hasta que al final divisaron un agujero muy pequeño en la pared, donde "aquel espíritu había escondido el escapulario fuertemente doblado y apretado ${ }^{49 "}$ (Nider 2019:23). Pasado un año de estos hechos, el fantasma se alejó de allí.

\footnotetext{
42 En España existe una gran tradición de ejércitos nocturnos en el caso de la Santa Compaña, reunión de las almas del Purgatorio que salen en la noche con el propósito de advertir en aquellas casas en las que habrá una defunción. Según la leyenda avisan, pero también pueden reprobar o cumplir una pena.

43 Deidad protogermánica de la cual y posteriormente derivará Odín.

44 Para consultar la historia completa en latín ver: Johannes Nider (versión Pedro Eduardo León Mescua), pp. 22-23.

45 "spiritus nocturnis temporibus multos inquietare solebat" (p. 23).

46 "strepitibus et fibulis ac pulsibus" (p. 23).

47 "spiritum ignoraret, nocte fantasma sensit quod sibi tunicam, quam supra se positam habuit, abstraxit" (p. 23).

48 "distracta uidit per spiritum in camera" (p. 23).

49 “enim spiritus ille scapulare strictissime inuolutum et glomeratum absconderat" (p. 23).
} 
Los elementos que podemos extraer del relato son los siguientes: La veracidad, que volvemos a apreciar en el texto porque es importante constatar los hechos ocurridos por personajes cuya autoridad y criterio son innegables para la creencia de la historia, así como la contextualización de un lugar real, en este caso, el Concilio de Constanza y un monasterio, en Núremberg. La noche, tópico repetido en las tres historias narradas. El fantasma, que solo molestaba al capellán y a los lugareños, no a las monjas del convento. Ente no maligno, que se divierte incordiando, alterando el orden, una especie de espíritu juguetón, "burlón", que con ruidos, silbidos y golpes inquieta a los inquilinos. Reconocemos en este comportamiento a los espíritus de las culturas paganas, duendecillos juguetones de la antigüedad, que se divierten provocando a los humanos. Lecouteux (1998) habla de apariciones del diablo producidas por el verbo inludere, "burlarse de", lo que podría identificarse con este tipo de espíritus burlones; relacionados a su vez con los antiguos Manes, almas de difuntos que no son ni buenas, ni malas. La pervivencia de estos fantasmas burlones se reproduce en cuentos posteriores de nuestra literatura, el propio Lope de Vega en La posada de los espíritus (1604) nos dice:

Estos demonios de poca monta se llaman en lengua italiana foletos y en la española trasgos $^{50}$ de cuyos rumores, juegos y burlas Guillermo Totanni cuenta, en su libro De Bello Daemonum, algunos ejemplos, llamándolos espíritus de la jerarquía menos noble (Muñoz Puelles 2014:38).

También Benito Feijoo en sus Cartas eruditas y curiosas (1742-1760), concretamente en la Carta XLI Sobre los duendes, hablando de las apariciones de los difuntos y para defender su tesis de que son meras ilusiones, definirá a los duendes como animales aéreos con comportamientos traviesos. Por último y para finalizar, respecto al tema del fantasma en la casa que ya aparecía en la cultura clásica, podemos afirmar que su evolución queda prácticamente inalterable a lo largo de los siglos. La casa se incluirá en los cronotopos de los lugares clásicos de aparecidos: casas, mansiones, cuevas o cementerios. Lugares cerrados que provocan la angustia de los protagonistas anticipando uno de los tópicos de la llamada literatura gótica, y que en el siglo XIX se transformará en el castillo ${ }^{51}$.

\section{Conclusiones}

Hemos intentado exponer con nuestras reflexiones en este artículo que la presencia del fantasma, que ya encontramos en la antigüedad, prevalecerá en la Edad Media, asimilando las creencias paganas e integrándolas en la fe del cristianismo. Los padres de

\footnotetext{
${ }^{30}$ Espíritus o duendes.

51 Hemos de recordar aquí, que la literatura gótica se inicia con la publicación de The Castle of Otranto (1764) de Horace Walpole, confiriendo al espacio escénico del castillo un lugar preferente dentro de este tipo de relatos.
} 
la Iglesia, Tertuliano y San Agustín, asentarán con sus escritos la teoría del alma que, desde su primer momento, contribuirá a aceptar que esta separación del hombre entre cuerpo y espíritu conlleva que, a veces, el alma no alcance su gloria eterna y pueda quedar atrapada, apareciéndose a los vivos. La cristianización de las creencias paganas comporta también que el último responsable de la aparición de los muertos sea Dios, pues solamente Él tiene la potestad de poder dar este consentimiento. A partir de aquí, aparecerán una gran cantidad de tratados didáctico-moralizantes que intentarán explicar el posible retorno de los muertos, por qué causas aparecen, cómo el hombre medieval tenía que prevenir con una buena vida cristiana el momento de su muerte, dónde iban las almas que no habían muerto en la gracia de Dios, y una infinidad de cuestiones teológicas y de comportamiento cotidiano que posibilitará que la creencia en estos muertos, espíritus o almas retornadas, se convierta en una idea creíble y aceptada en el ideario de esta época. En toda esta extensa producción tratadística queda claro que los espíritus que se aparecen e inquietan a los hombres "no son almas sino auténticos demonios", constante que se mantendrá hasta el siglo XVIII. No se cuestionarán las historias, ya que se tienen por verdaderas, y además, forman parte de los exempla para adaptar el tránsito de la vida terrenal a los preceptos de la fe cristiana. Por todo esto, será el demonio quien asuma la apariencia del difunto, siempre con el consentimiento divino. La imagen del fantasma que recogemos en los diferentes textos estudiados, no es la misma en la época clásica que en el medievo. En la antigüedad, el fantasma se presenta, generalmente durante los sueños, identificándose como una imagen, visión o sombra. En cambio, la iconografía del fantasma medieval cambiará respecto al de la antigüedad. El fantasma del medievo será un cuerpo tangible que en realidad contribuirá a propiciar la idea moderna que tenemos del ente. Apreciaremos también, en la imagen del muerto viviente, otras formas de representación que pueden materializarse como un espíritu invisible, un fantasma con sudario blanco, la calavera de las Danzas de la Muerte, incluso las transparencias del muerto de las Cántigas de Santa María; construyéndose toda una iconografía de lo macabro que influenciará no solamente al arte, sino a la literatura posterior de los siglos XVI y XVII ${ }^{52}$.

Es verdad que los relatos medievales a través de la tratadística solamente pretenden moralizar o satanizar, no podemos hablar de terror como placer literario, conceptos propios de la literatura gótica, porque la literatura sobrenatural es aceptada desde la maravilla cristiana para adoctrinar y poder evitar el castigo divino y la salvación eterna. Pero sí que nos imaginamos a los predicadores usando estos relatos en sus sermones y contribuyendo a provocar el miedo en los interlocutores, el miedo al castigo y a la condena eterna. Por ello, creemos que se pueden considerar un precedente de la literatura de terror. Evidentemente, no podemos hablar de terror fantástico, ni de relatos escritos para un público deseoso de una literatura del "sobresalto"; pero sí que podemos encontrar en estos tratados elementos fantasmales, como ya hemos

\footnotetext{
52 Para tener una visión literaria más amplia de relatos de estos siglos consultar: "Antecedentes góticos en relatos del XVI: el fantasma" (Agustí 2019).
} 
analizado, que permanecerán en el tiempo y que irán aportando tópicos literarios que contribuirán a la creación de la literatura de los cuentos de fantasmas del siglo XIX.

Con nuestro análisis del Formicarius hemos intentado acercarnos a un texto que, aunque ha sido traducido y comentado desde un punto de vista filológico, no ha estado trabajado como material literario que aporta elementos fantasmagóricos. Los fantasmas de los relatos son descritos por el autor como entes reales de tres historias que forman parte de los exempla, para reafirmar la creencia en la maldad de los demonios que se aparecen a los hombres, siempre con actitud engañosa. El primer fantasma es un ente, visión o sombra que podemos enmarcar perfectamente en la tradición fantasmal greco-latina, por sus características consustanciales, aunque al protagonista no se le aparece en un sueño. El segundo, se asemeja más al muerto viviente, aquel que regresa de la tumba para advertir de la existencia de una vida eterna y de los tormentos de ser un pecador, un fantasma tangente, visible que se aparece a un conocido, en este caso a su señor. Por último, el tercer fantasma pertenece a la clase de espíritus burlones que disfrutan causando pillerías a los humanos, que incordian pero no son dañinos. Espíritus que provienen de la cultura pagana y de un culto ancestral de la naturaleza.

Respecto a los ejércitos de fantasmas, el tratado afirma que si los antiguos ya atestiguaban que veían estas huestes de soldados con armas, caballos y carrozas; tales prodigios pueden revelar futuras guerras, pero a veces, son meros engaños del demonio y otras, anticipan algún castigo. Reconoce el texto en su fundamentación teológica que las almas pueden salir del cuerpo para atormentar, advertir o atemorizar, siguiendo los preceptos didácticomorales de la tratadística anterior y posterior. Incluso se afirma que son los demonios los que inquietan a los hombres o les hacen "chanzas", porque "Faunos" y "Panes", aparecen a veces seduciendo y burlándose de los humanos. Hay espíritus burlones que provocan la risa y la ilusión, y otros en cambio, tienen el poder de dañar y matar.

Podemos ratificar pues, con este estudio, que aunque no es pertinente hablar aquí de literatura de terror, sí que podemos constatar que existe una literatura preterrorífica ${ }^{53}$ que se asienta en relatos, como los que hemos analizado, que posteriormente, tendrá una confluencia en la llamada literatura gótica. Afirmamos, igualmente, que la aparición del fantasma en los cuentos de terror tiene una presencia medieval proveniente de todo un culto a la muerte y a la resurrección o retorno de los muertos, que se materializará en los tratados medievales de esta época.

\footnotetext{
53 Seguimos el término acuñado por Rafael Llopis (2013:287-288) que dice: "Lo numinioso, el sentimiento de pavor sagrado ante lo sobrenatural, encauzado en las religiones y luego negadas estas por el racionalismo, se encontró de pronto libre de expresarse como ficción". Por tanto, el primer miedo liberado fue el del tabú del miedo a los muertos. Define el autor lo preterrorífico como: "relatos anteriores al racionalismo, que contenían temas que más adelante utilizarían los autores de verdaderos cuentos de miedo".
} 


\section{Bibliografía}

Aguirre Castro, Mercedes (2006): "Fantasmas trágicos: algunas observaciones sobre su papel, aparición en escena e iconografía”, Cuadernos de Filología clásica: Estudios griegos e indoeuropeos, 16, pp. 107-120.

Agustí Aparisi, Carme (2019): "Antecedentes góticos en relatos del XVI: el fantasma”, Castilla. Estudios de literature, 10, pp. 103-125.

BARDEL, Ruth (2005): "Spectral Traces: Ggosts in Tragic Fragments”, en Fiona McHardy; James Robson; David Harvey. Lost Dramas of Classical Athens: Greek Tragic Fragments. Liverpool University Press.

Biblia de Jerusalén (1998): Bilbao, Descleé de Brouwer.

Bueno Domínguez, María Luisa (2015): "Las emociones medievales: el amor, el miedo y la muerte", Vínculos de Historia, 4, pp. 72-90.

Buxton, Richard (2014): "Fantasmas y religión entre los griegos: contextos y control", en Mercedes Aguirre Castro; Cristina Delgado Linacero; Ana González-Rivas (eds.), Fantasmas, aparecidos y muertos sin descanso. Madrid, Alabada Ediciones.

Calmet, Dom Augustin (1751): Traité sur les Apparitions des Esprits, et sur les vampires, ou les Revenans de Hongrie, de Moravie, \&c, Paris, Debure l'aîné. Gallica. Bibliothèque Nationale de France.

CAstaÑEgA, Martín de ([1529] (1997): Tratado de supersticiones y hechicerías. Estudio preliminar y notas de Fabián Alejandro Campagne. Buenos Aires, Universidad de Buenos Aires.

Delgado Linacero, Cristina (2014): "Seres maléficos, fantasmas y espíritus en Mesopotamia", en Mercedes Aguirre Castro; Cristina Delgado Linacero; Ana González-Rivas (eds.) Fantasmas, aparecidos y muertos sin descanso. Madrid, Alabada Ediciones, pp. 25-39.

Delumeau, Jean (1989): El miedo en Occidente. Madrid, Taurus.

EspinA, Alfonso de ([1458] 2003): Fortalitium fidei. Alicante, Biblioteca Virtual Miguel de Cervantes.

FEIJOO, Fray Benito Jerónimo (1742): Reflexiones críticas sobre las dos Dissertaciones, que en orden a Apariciones de Espíritus, y los llamados Vampiros, dio a luz poco há el célebre Benedictino, y famoso Expositor de la Biblia D. Agustín Calmet. "Cartas eruditas y curiosas" Tomo primero, Carta XLI. Biblioteca Feijoniana, en http://www. filosofia.org/bjf/bjfc420.htm [consultada 17/11/2019].

Flores JimÉnEZ, Alejandro (2008): "Sobre la actividad de los demonios: un tratado medieval Bizantino sobre Demonología”, Revista Digital Universitaria, volumen 9, 12- diciembre.

GAIL, Teresa; GARrido, Manuel (et al.) (2010): Historias de fantasmas y misterio de la antigüedad (Antología). Valencia, Editilde S.L. 
García JuRAdo, Francisco (2006): "Los cuentos de fantasmas: entre la literatura antigua y el relato gótico”. Culturas populares. Revista Electrónica 2 (mayo-agosto).

GonZÁLEZ ZyMLA, Herbert (2019): "La iconografía de lo macabro en Europa y sus posibles orígenes clásicos y orientales. Algunas manifestaciones en el arte español de los siglos XIV; XV y XVI", Revista digital de Iconografia Medieval, volumen XI, 21, pp. 1-53. GonZÁlez Zymla, Herbert (2014): "Visitas espectrales en la literatura y el arte de la Baja Edad Media: el encuentro de los tres vivos y los tres muertos y la danza macabra", en Mercedes Aguirre Castro; Cristina Delgado Linacero; Ana González-Rivas (eds.) Fantasmas, aparecidos y muertos sin descanso. Madrid, Alabada Ediciones, pp. 181-199.

GonzÁlez Zymla, Herbert (2011): "El encuentro de los tres vivos y los tres muertos", Revista digital de Iconografía Medieval, volumen III, 6, pp. 51-82.

Guzmán Almagro, Alejandra (2017): Fantasmas, apariciones y regresados del Más Allá. Bilbao, Sans Soleil Ediciones.

Guzmán Almagro, Alejandra (2015): "Historias de fantasmas y lugares encantados: pervivencia de un género de los exempla de Petrus Thyraeus", en M. Tersa Muñoz Gracía de Iturrospe y Leticia Carrasco (eds.) Micellanea Latina. Madrid, Selat, pp. 565-569.

Guzmán Almagro, Alejandra (2013): "Demonios, fantasmas y máscaras en la Antigüedad: consideraciones sobre el término Larva y sus significados", en EMERITA Revista de Lingüística y Filología Clásica, LXXXI-1, pp. 183-202.

Haindl Ugarte, Ana Luisa (2013): "Ars bene moriendi: el Arte de la Buena Muerte", Revista Chilena de Estudios Medievales, 3, pp. 89-108.

Haindl Ugarte, Ana Luisa (2009): "La muerte en la Edad Media", Revista Electrónica Historias del Orbis Terrarum, 1. http://www.orbisterrarum.d [consultada 28/10/2019]. Heisterbach, Cesáreo de (1223): Libri VIII, Dialogus Miraculorum, en http://www. iglesiapueblonuevo.es/index.php?codigo=bio_cesareoh. [consultada 29/10/2019].

Hipona, Agustín de (s.f.): El espíritu y el alma. Traductor: P. Teodoro Calvo Madrid. https:/www.augustinus.it/spagnolo/attribuiti_02/index.htm [consultada 17/11/2019].

KLEIN, Rainer W. (2004): Espíritus, fantasmas y otras apariciones. Buenos Aires, Grupo Imaginador Ediciones.

LAVATER, Ludwig (1571): Trois libres des apparitions des esprits, fantomes prodiges et accidens merveilleux qui precedent souventes fois la mort de quelque personnage renommé, ou un grand changement és choses de ce monde. Paris, Imprimerie de François Perrin. Gallica. Bibliothèque nationale de France.

Lecouteux, Claude (2009): Fantômes et Revenants au Moyen Âge. Paris, Éditions Imago.

Lecouteux, Claude (1998): Fantasmas y aparecidos en la Edad Media. Barcelona, José J. de Olañeta, Editor.

Le Goff, Jacques (2002): Lo maravilloso y lo cotidiano en el Occidente medieval. Barcelona, Gedisa, S.A.

Le Goff, Jacques (1999): La civilización del occidente medieval. Barcelona, Paidós. 
Lope de Vega, Félix (1604-[2014]). "La posada de los espíritus", en Fantasmas y Aparecidos. Selección de Vicente Muñoz Puelles, Alzira, Clásicos Algar.

Llopis, Rafael (2013): Historia natural de los cuentos de miedo. Madrid, Fuentetaja.

Mitre Fernández, Emilio (2003-2004): "Muerte y modelos de Muerte en la Edad Media Clásica", Edad Media. Revista de Historia, 6, pp. 11-31.

MuÑoz GarCíA, M. Teresa (2014): "Fantasmas y daemones litterati: apariciones de muertos insignes desde la Antigüedad", en Mercedes Aguirre Castro; Cristina Delgado Linacero; Ana González-Rivas (eds.) Fantasmas, aparecidos y muertos sin descanso. Madrid: Alabada Ediciones, pp. 117-130.

Muñoz Puelles, Vicente (2014): Fantasmas y Aparecidos. Alzira, Clásicos Algar.

Nider, Johannes (1437-1438 [2019]): El libro quinto del Formicarius. Fantasmas, brujería, endemoniados y exorcismo. Segunda edición crítica. Texto latino establecido, anotado y traducido al castellano por Pedro Eduardo León Mescua. Valencia.

Ogden, Daniel (2014): "Fantasmas romanos", en Mercedes Aguirre Castro; Cristina Delgado Linacero; Ana González-Rivas (eds.), Fantasmas, aparecidos y muertos sin descanso. Madrid, Alabada Ediciones.

PorRas GiL, María Concepción (1993): "El concepto de la muerte a finales de la edad Media”, en B.I.F.G. Burgos. Tomo LXV, 206, pp. 9-17.

Real Academia Española. Diccionario de la lengua española. https://dle.rae.es/diccionario [consultada 21/05/20].

Río, Martín del ([1551-1608] 1991): Disquisiciones mágicas. Traducción y Edición de Jesús Moya. Madrid, Hiperión.

Sснмітт, Jean Claude (1994): Les revenants. Les vivants et les morts dans la société médiévale. Paris, Editions Gallimard.

SHARPE, John (1815): The History of the Kings of England and the Modern History of William Malmesbury. London, W. Bulmer and co. Cleveland-Row.

Sprenger, Jacobo; Institoris, Enrique [1486 (2004)]: Malleus Maleficarum. Traductor Miguel Jiménez Monteserín. Valladolid, Maxtor.

Taillepied, Nöel (1602): Traite de l'Apparition des Esprits. Roven, Chez Osmont. Books Google. 
